\title{
Ampliando o letramento escolar: da leitura de anúncios em vídeo e a produção de comentários
}

Expanding school literacy: from Reading video ads and production of comments

\author{
Maria do Rosário da Silva de Albuquerque Barbosa \\ Universidade Federal Pernambuco - UFPE - Pernambuco - Brasil
}

\section{Érika Regia dos Santos Silva}

Universidade Federal do Rio de Janeiro - UFRJ - Rio de Janeiro - Brasil

\begin{abstract}
Resumo: Este artigo objetiva explicitar como um projeto didático pode promover o letramento multimodal no Ensino Fundamental, considerando a leitura de anúncios em vídeo e a produção de Comentários em sala de aula. Desenvolvido durante uma proposta de intervenção didática, promovida no Mestrado Profissional em Letras (PROFLETRAS), o projeto segue os princípios teóricos e metodológicos da Escola de Sydney (MARTIN; ROSE, 2008; ROSE; MARTIN, 2012), considerando o Ciclo de Ensino e Aprendizagem, especificamente o Projeto Ler para Aprender (ROSE; MARTIN, 2012), adaptando-as à realidade brasileira, especialmente ao currículo de Língua Portuguesa do Ensino Fundamental. Estabelece-se um diálogo entre a Linguística Sistêmico-Funcional de Halliday e Matthiessen (2004) e a Gramática do Design Visual de Kress e van Leeuwen (2006), no que tange aos estudos da linguagem e à construção de significados. Foram utilizados três anúncios em vídeo, divulgados na plataforma do YouTube e comentários escritos em sala de aula por estudantes do 9ำ ano do Ensino Fundamental. Trata-se de uma pesquisa interpretativa, envolvendo oficinas pedagógicas que traduzem uma temática do contexto social dos estudantes. Os resultados mostram que os aprendizes mobilizaram significados imagéticos para ler e produzir gêneros de textos e que as oficinas pedagógicas, sob a orientação da proposta do projeto Ler para Aprender, podem possibilitar o letramento multimodal e ampliar a construção de significados representacionais, interativos e composicionais e, dessa forma, garantir a formação crítica da leitura e da escrita em contextos escolares.
\end{abstract}

Palavras-chave: Letramento multimodal. Construção de significados. Anúncio em vídeo. Comentários.

\begin{abstract}
This article aims to explain how a didactic project promotes multimodal literacy in elementary school, considering the reading of video ads and the production of Comments in the classroom. Developed during a didactic intervention proposal, promoted in the Professional Masters in Letters (PROFLETRAS). It follows the Sydney School's theoretical and methodological principles (MARTIN; ROSE, 2008; ROSE; MARTIN, 2012), considering the Teaching and Learning Cycle, specifically the Ler para Aprender Project (ROSE; MARTIN, 2012), adapting them to reality especially the Portuguese language curriculum for elementary school. A dialogue is established between the Systemic-Functional Linguistics of Halliday and Matthiessen (2004) and the Grammar of Visual Design by Kress and van Leeuwen (2006), with regard to language studies and the construction of meanings. Two video ads were used, published on the YouTube platform and comments written in the classroom by 9th grade students. It is an interpretative research, involving pedagogical workshops that translate a theme of the students' social context. The results show that elementary school learners mobilize imagery meanings to read and produce text genres and that pedagogical workshops, under the guidance of the Ler para Aprender project proposal, can enable multimodal literacy and expand the construction of representational, interactive and compositional and, thus, guarantee the critical formation of reading and writing in school contexts.
\end{abstract}

Keywords: Multimodal literacy. Construction of meanings. Video ad. Comments. 


\section{Introdução}

Este estudo traz resultados de uma experiência didática desenvolvida no Programa de Mestrado Profissional em Letras (PROFLETRAS) ${ }^{1}$ com o objetivo de promover uma intervenção no ensino da leitura e da escrita na escola básica. Dessa forma, mantém princípios didáticos dos Parâmetros Curriculares Nacionais (PCNs, 2008) em diálogo com a Base Nacional Curricular Comum (BNCC, 2018). Mostra também que os gêneros de textos por serem o cerne do aprendizado em Língua Portuguesa são capazes de promover 0 ensino de modo contextualizado e articulado ao uso social da língua. Além disso, as transformações tecnológicas, ocorridas nas últimas décadas, vêm contribuindo para que os estudos da linguagem evoluem consideravelmente, já que esses avanços podem ser visualizados com o aumento vertiginoso dos textos multimodais na sociedade atual.

$\mathrm{Na}$ busca pela ampliação do letramento na escola, os gêneros de textos passaram a ser elaborados de modo mais interativo, utilizando diferentes recursos em sua composição que exige do leitor novas habilidades de leitura e de escrita. Essas mudanças incentivam novas formas de letramento para a sala de aula, ligando a leitura e a produção de texto à multimodalidade e, dessa forma, aponta caminhos para uma abordagem de leitura capaz de contemplar a linguagem verbal e a não verbal. Desse modo, realizamos uma experiência didática numa turma de 9a ano do ensino fundamental de uma escola pública do Estado de Pernambuco ${ }^{2}$, cujos resultados, no âmbito da leitura e da escrita, indicam que há dificuldade para inferir informações e compreender as relações entre a linguagem verbal e não verbal.

Para realização deste estudo, consideramos dois gêneros de textos contemplados na proposta curricular do 9ำ ano do Ensino Fundamental: anúncios e comentários. Utilizamos anúncios em vídeo divulgados no YouTube por ser uma plataforma de uso

\footnotetext{
${ }^{1}$ Este artigo é um recorte dos resultados apresentados na Dissertação de Mestrado Da leitura de anúncios em vídeo à produção de comentários: um estudo de significados à
}

dos estudantes e por contemplar uma temática do cotidiano dos estudantes: compra e venda de produtos Avon. A Avon, ainda é hoje, no contexto rural dos estudantes envolvidos neste estudo, a forma mais divulgada de comprar e vender cosméticos por meio de uma revista de divulgação impressa e digital.

Nossa abordagem didática, inspirada no Ciclo de Ensino e Aprendizagem Ler para Aprender, no âmbito da Pedagogia de Gêneros, proposto por Martin e Rose (2012), cria um encadeamento sistemático de ações no processo de aprendizagem, permitindo que os alunos do $9^{\circ}$ ano do Ensino Fundamental desenvolvam e/ou aprimorem o letramento multimodal. Para tanto, realizamos oficinas pedagógicas com temáticas do contexto social dos estudantes, destacando um contexto de letramento, a partir da leitura de anúncios em vídeos e sua relação com a percepção dos significados por meio de comentários escritos. Desse modo, o objetivo deste artigo é explicitar como um projeto didático promove o letramento multimodal no Ensino Fundamental, considerando a leitura de anúncios em vídeo e a produção de comentários em sala de aula.

Para fundamentar esta pesquisa, utilizamos estudos teóricos e metodológicos de Halliday (1976); Halliday e Hasan (1989); Halliday e Matthiessen (2004), destacando os conceitos de contexto e de cultura, bem como as metafunções da linguagem. Abordamos, também, a Gramática do Design Visual de Kress e van Leeuwen (2006) que aprofunda a relação entre palavra e imagem e a construção de significados. Consideramos a Pedagogia de Gêneros e o Ciclo de Ensino Aprendizagem com as contribuições teóricas e metodológicas de Martin e Rose (2012) e Rothery (1996), especificamente o Ciclo Ler para Aprender.

Somando-se a esses estudos e outros estudos realizados no Brasil, neste artigo, consolidamos mais uma experiência didática capaz de promover o letramento e ampliar reflexões teóricas e práticas no que tange à formação do leitor e do escritor.

luz da gramática do design visual (SANTOS; SILVA, 2020).

$2 \mathrm{O}$ estudo foi realizado numa escola municipal rural do Interior de Pernambuco - Região Nordeste do Brasil. 


\section{Linguística Sistêmico-Funcional e a} Gramática do Design Visual

A Linguística Sistêmico-Funcional (LSF) que tem como principal expoente o linguista britânico Halliday (1976) analisa a língua nas suas diferentes funções sociais, na qual cada indivíduo realiza e constrói significados por meio das funções e relações disponíveis no sistema e não de maneira desvinculada do uso, como ocorria na linguística tradicional. De acordo com Muniz da Silva (2018, p.318), a "LSF teoriza a língua em termos da relação entre os significados construídos em um determinado contexto e os recursos linguísticos que realizam esses significados". Portanto, o ponto de partida da análise dessa abordagem teórica não é a oração, mas o todo (texto), pois o significado é determinante para a definição da forma.

Nesse contexto, Halliday (1976) defende que a língua está organizada para construir, de forma simultânea, três tipos de significados ou metafunções: ideacional, interpessoal e textual. A ideacional mantém relação com a variável de campo, por meio dela é possível organizar as ideias do indivíduo e representálas na oração. Nessa perspectiva, Halliday; Matthiessen (2004) consideram que a metafunção ideacional se efetiva no uso da língua a fim de exprimir as experiências de ordem externa e interna dos usuários. A metafunção interpessoal está relacionada com a forma de organização da mensagem, levando em consideração que ela é o meio de interação que envolve quem fala, quem escreve e o público, podendo o sujeito expressar seus julgamentos e opiniões. E, para Halliday e Matthiessen (2004), a metafunção textual está relacionada com a forma como os textos são construídos. O modo como são compostos refletem as funções experiencial e interpessoal num todo coerente e coesivo que permite a interação entre quem fala e quem ouve.

Seguindo os princípios da LSF, surge a Gramática do design Visual (GDV), representada por Kress e van Leeuwen (2006), que tinha o objetivo de correlacionar as noções teóricas de metafunção de Halliday com a análise de imagens. Essa gramática procura atender às necessidades de uma sociedade que possui práticas comunicativas marcadas pela presença de textos híbridos e que solicita do leitor diferentes artifícios para a leitura de textos visuais.

Esses autores sugerem que, semelhante à forma como os textos verbais são analisados, é preciso descrever o modo como os elementos que compõem as imagens se combinam para construir os sentidos de um texto. Por isso, eles defendem que a linguagem visual pode ser aprendida, e, portanto, deve ser ensinada nas escolas. Nesse contexto, Kress e Van Leeuwen (2006) recuperaram as metafunções propostas por Halliday (1985) - interpessoal, ideacional e textual-, aplicando-as às análises de textos multimodais e buscando interpretar experiências e formas de interação social a partir de um ponto de vista semiótico. Assim, passam a considerar três outras (meta)funções: a representacional, interacional e composicional. A metafunção representacional está relacionada com a forma como os participantes interativos (aquele que fala, ouve, lê, observa) e representados (sujeitos da comunicação) são mostrados nas imagens.

A metafunção interativa diz respeito à relação entre quem observa e o que é observado, assim, consoante Gualberto (2016, p. 67), “[...] busca-se descobrir como a imagem se coloca para seu observador - de forma imponente, convidativa, distante, superior, formal, pessoal, entre outras." E a metafunção composicional está voltada para a maneira como os elementos da imagem se unem para se integrar com os elementos representacionais $e$ interativos. A fim de analisar de forma mais complexa os significados composicionais das imagens, Kress e van Leeuwen ([1996] 2006) criaram um mecanismo considerando as categorias de valor da informação, saliência, estruturação/ enquadramento.

Diante do que foi visto, e de acordo com Almeida (2009, p.187), a proposta exposta na GDV indica que o meio semiótico visual, assemelhando-se ao verbal, pode atuar como um sistema independente de comunicação e significados e que por essa razão possibilita que possamos realizar "análises mais 
sistemáticas de imagens e a categorização de padrões visuais sintáticos".

\section{Pedagogia de Gêneros e o Projeto Ler} para Aprender

Estudiosos de Sidney, especialmente Joan Rothery e Jim Martin, desenvolveram em 1979 um programa de letramento para atender as crianças carentes das escolas de anos iniciais do ensino básico da Austrália, utilizando uma abordagem denominada "genre writin" (escrita de gêneros) que era eficaz no ensino da escrita. Inicialmente, o projeto tinha por objetivo criar uma pedagogia capaz de atenuar o insucesso escolar resultante das exigências de textos escritos escolares, surgindo assim o conceito de gênero como um processo social orientado.

A Pedagogia de Gênero que se desenvolveu com base em três principais projetos: Writing Project and Language and Social Power (Projeto de Escrita e Linguagem e Poder Social) desenvolvido nos anos oitenta; Write it Right ( Escrever Certo) que apresentou os gêneros que os alunos do ensino secundário precisam ler e escrever, e teve lugar nos anos noventa; Reading to Learn ( Ler para Aprender) que, nos primeiros anos do século XXI desenvolveu uma metodologia que integrava a leitura e a escrita na aprendizagem do currículo no ensino básico, secundário e universitário.

Durante a aplicação dos projetos que marcaram a difusão da pedagogia de gêneros, desenvolveu-se, ao longo do processo de investigação e aplicação, o Ciclo de Ensino e Aprendizagem do programa Ler para Aprender. O ponto de partida dessa metodologia é que a leitura tem estreita relação com a escrita, mostrando quem lê mais escreve melhor. Dessa forma, sugere-se atividades que agregam leitura e escrita atreladas aos conteúdos curriculares de acordo com o nível escolar dos estudantes e com o contexto social.

O projeto Ler para Aprender é organizado em nove estratégias que são distribuídas em três níveis utilizados sistematicamente pelos professores para contribuir com o desenvolvimento das habilidades de leitura e interpretação dos alunos. Seguindo a perspectiva do ciclo de ensino aprendizagem, Martin (2016) descreve de forma detalhada as etapas que aparecem em Rose (2016), conforme segue:

\section{Figura 1- Ciclo de ensino-aprendizagem da} Pedagogia Ler para Aprender

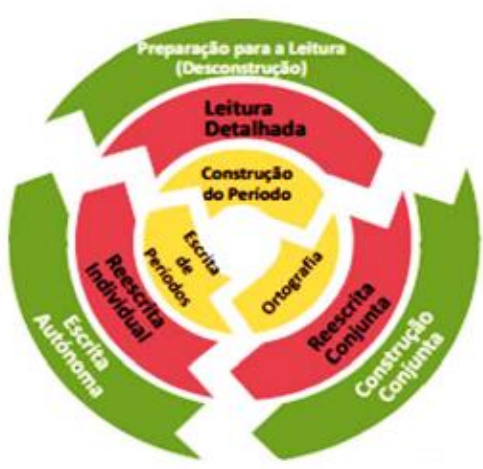

FONTE: Adaptado de Rose e Martin (2012)

No nível um encontram-se as etapas de Preparação antes da Leitura, Construção Conjunta e Escrita Independente. A Preparação para a Leitura, segundo Rose (2016), serve para que todos os alunos possam acompanhar o texto que está sendo lido durante a aula, como também para que participem da criação de atividades ao longo e depois da leitura. Sendo assim, a Preparação se caracteriza como uma espécie de roteiro que deve ser seguido, considerando os elementos lexicais constitutivos do texto. Nesse momento, o reconhecimento da tipologia e sua forma de estruturação pode permitir um melhor entendimento do gênero e a maneira como ele se organiza.

A Construção Conjunta é o momento em que o texto, tomado como referência, é desconstruído com o objetivo de levar os estudantes a produzirem um novo texto, de forma coletiva, tendo em vista que eles já conhecem a organização textual do gênero. Já na Construção Individual, os estudantes a identificam e aplicam os padrões linguísticos apreendidos, de acordo com o exemplo de texto estudado, utilizando os conhecimentos construídos na produção de seus futuros textos.

O nível dois envolve as etapas de Leitura Detalhada, Reescrita Conjunta, e Reescrita individual. 
Na primeira etapa os alunos devem ser orientados pelo professor a lerem o texto de forma segmentada, identificando e debatendo o sentido de cada uma das partes que integram o texto. O papel desse estágio é, segundo Rose (2016, p. 323), "permitir que todos os estudantes leiam a passagem com compreensão completa e fluência e reconheçam as escolhas linguísticas feitas pelo autor'. Assim, eles podem reconhecê-las em outros textos para depois inseri-las em seus próprios".

Seguidamente, temos a "Reescrita Conjunta". Nesse estágio, leva-se em consideração, principalmente, os aspectos de ordem gramatical que estão presentes nos trechos verificados e selecionados previamente pelo professor. Esse momento é de grande importância para que os estudantes consigam identificar os padrões de linguagem utilizados e empregá-los em situações parecidas. Dessa forma, é nesta ocasião que os estudantes exercitam a identificação de questões de escolhas lexicais, gramaticais e discursivas feitas pelo autor, para, a partir de então, começar a reescrevê-las. Depois disso, os estudantes utilizam a mesma atividade na Reescrita Individual. E, o nível três corresponde às etapas de elaboração de frases, ortografia e escrita de períodos e caracteriza-se pelo apoio aos alunos para desenvolver habilidades no âmbito da leitura, ortografia e escrita.

Sendo assim, a aplicação sequencial dos níveis do Ciclo de Aprendizagem direciona para a construção do texto de forma processual e sistemática, com intervenção do professor quando se faz necessária, como por exemplo, no processo de reescrita. Contudo, mesmo apresentando uma ordem categórica de seus níveis, o Ciclo de Aprendizagem se caracteriza como uma metodologia bastante flexível.

\section{Projeto de leitura e escrita inspirado no} projeto Ler para Aprender

Em pesquisa interventiva didática desenvolvida no PROFLETRAS, optamos por um projeto de leitura e de escrita $^{3}$ que possibilite ao estudante uma formação leitora e escritora crítica, tendo o contexto social como elo responsável por essa formação e a escola como garantidora desse processo, uma vez que a escola pode possibilitar ações didáticas que envolvam o aluno em práticas sociais diversas se utilizando da leitura e da escrita ${ }^{3}$. Para tanto, atentamos para o conceito de gênero como "um processo social orientado para um fim específico" (ROSE; MARTIN, 2012, p. 1) que surgiu com as pesquisas dos tipos de escrita na escola primária australiana e desencadeou a Pedagogia de Gêneros.

\subsection{Sobre as ações didáticas}

Esta proposta resulta num projeto didático para $9^{\circ}$ ano do Ensino Fundamental, inspirado no Projeto Ler para Aprender do letramento australiano, contudo não se distancia da proposta curricular da escola ${ }^{4}$ utilizada no Brasil. Esse projeto é formado por quarenta horas aulas e constituído por quatro etapas, conforme sugere o projeto Ler par Aprender (ROSE; MARTIN, 2012) - Preparação para a Leitura, Leitura detalhada; Construção Conjunta e Construção Independente - e dialoga com quatro oficinas pedagógicas (PAVIANI; FONTANA, 2009) e oito atividades de leitura e de escrita, contemplando três anúncios em vídeos (Quadro 1).

\footnotetext{
3 PROJETO DIDATIZANDO A LEITURA DE ANÚNCIOS (DILAN) - Projeto desenvolvido no segundo bimestre de
}

2019 e é composto por trinta e seis horas aulas (SANTOS; SILVA, 2020). 


\section{Quadro 1: Anúncios em vídeo estudos no projeto de leitura e escrita}

\begin{tabular}{|c|c|c|}
\hline $\begin{array}{c}\text { Revele } \\
\text { Seu } \\
\text { Máximo } \\
\text { com o } \\
\text { novo } \\
\text { Epic | } \\
\text { AVON } \\
\text { (AN-01) }\end{array}$ & $\begin{array}{c}4 \text { de } \\
\text { janeiro } \\
\text { de } 2018\end{array}$ & $\begin{array}{l}\text { https://www.youtube.com/watch?v=4l-y4s- } \\
\text { oQMI }\end{array}$ \\
\hline $\begin{array}{l}\text { Batom } \\
\text { em pó } \\
\text { com } \\
\text { efeito } \\
\text { nuvem } \\
\text { matte } \\
\text { (AN-02) }\end{array}$ & $\begin{array}{c}27 \text { de } \\
\text { maio de } \\
2019\end{array}$ & $\begin{array}{l}\text { https://www.youtube.com/watch?v=qylDnh3 } \\
\underline{\text { Wtfl }}\end{array}$ \\
\hline $\begin{array}{c}\text { Veio pra } \\
\text { ficar - O } \\
\text { Batom } \\
\text { da Marta } \\
\text { (AN-03) }\end{array}$ & $\begin{array}{c}22 \text { de } \\
\text { julho de } \\
2019\end{array}$ & $\begin{array}{l}\text { https://www.youtube.com/watch?v=GIMM5x } \\
\text { DCeNE }\end{array}$ \\
\hline
\end{tabular}

FONTE: YouTube $(2018,2019)$ - Projeto DILAN- adaptado de Silva Santos (2020)

Na primeira etapa (Quadro 1), experienciamos quatro oficinas pedagógicas no intuito de preparar o aluno para a leitura dos anúncios em vídeos selecionados para o projeto. Nesse momento, destacamos características do gênero anúncio - seja publicitário ou propagandístico-comparamos com a leitura de outro de tipo de gênero midiático (charge), estimulamos uma discussão sobre o assunto que seria discutido durante todo o projeto, além de situarmos o aluno na plataforma digital em que se encontram os gêneros de texto contemplados. Com isso, mostramos aos alunos a relevância entre o diálogo texto verbal e não verbal no processo de leitura e escrita, considerando a construção de significados a partir das imagens do anúncio.

\section{Quadro 2: Etapa 01 - Preparação para a Leitura} (PL)

\begin{tabular}{|cc|l|c|}
\hline \multicolumn{2}{|c|}{ OFICINAS } & \multicolumn{1}{c|}{ ATIVIDADES } & CH \\
\hline 01 & $\begin{array}{c}\text { A organização } \\
\text { do gênero }\end{array}$ & $\begin{array}{l}\text { Exposição: gênero } \\
\text { anúncio publicitário }\end{array}$ & \\
\cline { 3 - 4 } & $\begin{array}{l}\text { Exposição: gênero } \\
\text { anúncio de propaganda }\end{array}$ & \\
\hline 02 & O assunto & $\begin{array}{l}\text { Leitura: charges sobre o } \\
\text { consumismo }\end{array}$ & \\
\cline { 3 - 4 } & $\begin{array}{l}\text { Debate: temática; o } \\
\text { consumismo }\end{array}$ & \\
\hline 03 & $\begin{array}{l}\text { O anúncio em } \\
\text { vídeo }\end{array}$ & $\begin{array}{l}\text { Roda de conversa: o } \\
\text { YouTube }\end{array}$ & \\
\cline { 3 - 5 } & $\begin{array}{l}\text { Trocando ideias: o } \\
\text { anúncio Revele seu } \\
\text { Máximo }\end{array}$ & \\
\hline
\end{tabular}

\begin{tabular}{|l|l|l|l|}
\hline & $\begin{array}{l}\text { Atividade escrita: os } \\
\text { significados do anúncio }\end{array}$ & \\
\hline 04 & $\begin{array}{c}\text { Os } \\
\text { significados }\end{array}$ & $\begin{array}{l}\text { Produção escrita: } \\
\text { comentários }\end{array}$ & $4 \mathrm{~h}$ \\
\hline
\end{tabular}

FONTE: Projeto DILAN - adaptado de Silva e Santos (2020)

Na tentativa de envolver o aluno no processo de letramento multimodal, nesta primeira etapa (Quadro 2), trazemos à tona os contextos de cultura e de situação, instrumentalizando o professor para estudos do contexto social e considerando as práticas sociais da linguagem, especialmente, as construídas na interação cotidiana. Para isso, essas oficinas exploram os conhecimentos prévios dos alunos acerca de anúncios publicitários e de propaganda.

Destacamos, também, a plataforma YouTube para iniciar a apreciação do anúncio "Revele seu máximo (AN-01)" publicado pela Avon. Essa exploração inicial possibilita ao professor e ao aluno o reconhecimento da plataforma, confirmando o fato de que o conhecimento também pode efetivado através da reconfiguração dos meios mais informais de aprendizagem, pois o Youtube é uma plataforma interativa que pode ser utilizada como recurso didático em contexto de ensino e pode possibilitar a criação de práticas em que os alunos e professores tornam-se coautores na construção do conhecimento. Ao término dessa etapa, os alunos produziram um comentário escrito, evidenciando suas primeiras percepções sobre os significados construídos pelo anúncio publicado no Youtube.

Na segunda etapa (Quadro 3), para obter uma leitura detalhada dos anúncios em vídeos estudados, elegemos dois anúncios AN-02 e AN-03, destacando a função social, os significados das imagens e a estrutura visual.

\section{Quadro 3: Etapa 02 - Leitura Detalhada}

\begin{tabular}{|l|c|l|c|}
\hline 05 & $\begin{array}{c}\text { A função } \\
\text { social }\end{array}$ & $\begin{array}{l}\text { Trocando opiniões: } \\
\text { função social do } \\
\text { gênero anúncio. }\end{array}$ & $2 \mathrm{~h}$ \\
\hline $\mathbf{0 6}$ & $\begin{array}{c}\text { As imagens } \\
\text { do gênero } \\
\text { de texto }\end{array}$ & $\begin{array}{l}\text { Leitura e atividade } \\
\text { escrita: construção de } \\
\text { significados 8h do } \\
\text { anúncio "Batom em Pó }\end{array}$ & 8h \\
\hline
\end{tabular}




\begin{tabular}{|l|c|l|c|}
\hline \multirow{2}{*}{$\mathbf{0 7}$} & $\begin{array}{l}\text { A } \\
\text { composição } \\
\text { do anúncio }\end{array}$ & $\begin{array}{l}\text { Atividade efeito nuvem } \\
\text { matte" (AN-02). }\end{array}$ & \\
\hline & $\begin{array}{l}\text { elementos do gênero } \\
\text { do anúncio }\end{array}$ & \multirow{2}{*}{$\begin{array}{l}\text { Leitura e atividade } \\
\text { escrita: o verbal e do } \\
\text { não verbal no anúncio } \\
\text { "Batom Matte em pó } \\
\text { da Avon". (AN-02). }\end{array}$} & \\
\hline
\end{tabular}

FONTE: Projeto DILAN- adaptado de Silva e Santos (2020)

Na etapa 02, evidenciamos, especialmente, as características do gênero anúncio em vídeo por meio de atividades pautadas nos significados representacional, interativo e composicional, levando em consideração o contexto social do aluno. Esse momento convém para auxiliar os estudantes na posterior produção de textos - Comentários escritos acerca dos significados construídos pelos anúncios AN-02 e AN-03 e percebidos pelos alunos no momento da leitura em sala de aula. Essa abordagem característica da pedagogia de gêneros contribui para que haja uma autonomia dos alunos no que diz respeito ao reconhecimento do que será solicitada no processo de escrita, assim a atividade de produção passa a fazer mais sentido para eles.

\section{Quadro 4: Etapa 03- Construção Conjunta}

\begin{tabular}{|c|l|l|l|}
08 & $\begin{array}{c}\text { Um olhar para } \\
\text { a produção do } \\
\text { texto escrito }\end{array}$ & $\begin{array}{l}\text { Debate - Percepção } \\
\text { dos significados do } \\
\text { anúncio Veio pra Ficar } \\
\text { (AN -03) }\end{array}$ & $4 \mathrm{~h}$ \\
& $\begin{array}{l}\text { Produção textual } \\
\text { coletiva: escrita de } \\
\text { comentários }\end{array}$ \\
\end{tabular}

FONTE: Projeto DILAN- adaptado de Silva e Santos (2020)

$\mathrm{Na}$ terceira etapa (Quadro 4), construção conjunta, foi o momento em que os alunos usaram o conhecimento sobre o gênero em discussão e, com o grupo de colegas e auxílio da professora, foram motivados a criar um gênero de texto coletivamente. As ideias dadas pela turma foram anotadas para que eles visualizassem na hora da escrita, sendo 0 professor o responsável por sintetizá-las e escrevê-las na lousa.
Nessa perspectiva, Rose e Martin (2012) lembram que esses tipos de atividades de ensino podem munir todos os estudantes com habilidades significativas, desde que estejam integradas ao currículo escolar.

\section{Quadro 5- Etapa 04: Construção Independente}

\begin{tabular}{|c|c|c|c|}
\hline \multirow[t]{2}{*}{09} & \multirow{2}{*}{$\begin{array}{l}\text { Um olhar para o } \\
\text { letramento } \\
\text { midiático } \\
\text { multimodal }\end{array}$} & $\begin{array}{l}\text { Reescrita de } \\
\text { comentários: } \\
\text { construção individual }\end{array}$ & \multirow{2}{*}{$4 \mathrm{~h}$} \\
\hline & & $\begin{array}{l}\text { Publicação de } \\
\text { comentários no canal } \\
\text { do You Tube no qual o } \\
\text { anúncio em vídeo (01) } \\
\text { circula. }\end{array}$ & \\
\hline \multicolumn{3}{|c|}{ CARGA HORÁRIA TOTAL } & $4 \mathrm{~h}$ \\
\hline
\end{tabular}

$\mathrm{Na}$ etapa 04 (Quadro 5), realizamos a Construção Independente, momento em que os alunos produzem o gênero Comentário sobre o primeiro anúncio trabalhado na etapa 01 (Revele Seu Máximo com o novo Epic). Nessa produção, os estudantes apresentam suas percepções acerca da construção dos significados do gênero anúncio em vídeo. Essa atividade de produção escrita materializa a leitura da temática do anúncio e ocorre depois do estudante participar de todas as atividades do projeto de leitura e escrita experienciado na escola.

\section{2 Sobre os resultados do Projeto} Didático

Após a vivência do projeto didático, notamos que a percepção dos alunos a respeito dos significados construídos pelos anúncios tornou-se significativa e crítica, uma vez que a estrutura representacional análoga à metafunção ideacional pode revelar aos modos de representação do mundo a partir de estruturas visuais, mostrado as diversas relações entre os participantes representados (pessoas, objetos, lugares, formas geométricas e/ou abstratas).

As etapas sugeridas pelo projeto Ler para Aprender (ROSE; MARTIN, 2012) promoveram, com a inserção das diversas atividades e oficinas de leitura e 
escrita em sala de aula, produção de comentários, sinalizando significados das imagens do anúncio, por meio de comentários. Todos os significados foram materializados nos comentário (C1) e comentário 2(C2): C1 foi produzido na etapa 01 e (C2) na etapa 04 do projeto de leitura e escrita desenvolvido no Ensino Fundamental.

Para esse artigo, consideramos apenas um dos comentários produzidos pelos alunos que participaram efetivamente de todas as oficinas da proposta didática. Esse estudo revela como se configura a leitura de um texto multimodal, especificamente, anúncio publicitário da empresa Avon que circula na plataforma do YouTube, focando na percepção dos significados - representacionais, composicionais e interativos - materializados em comentários escritos.

\subsubsection{Percepção dos significados das} imagens: 0 anúncio em vídeo

Durante o projeto de leitura, foram estudados três anúncios em vídeo, como mencionado anteriormente. Para este estudo, destacamos os significados expressos no anúncio "Revele Seu Máximo com o novo Epic" - AVON (AN-01) a partir da leitura das imagens, necessárias para o aluno entender o propósito social do gênero, destacando o contexto social e o assunto; e compreender o assunto do anúncio. O anúncio AN-01 apresenta a atriz Paola Oliveira com protagonista (Quadro 06 - Imagens 01, 02, 03 e 04). Segundo a opinião da direção de marketing da empresa Avon no Brasil, a atriz foi escolhida pela beleza e pelo fato de ela ter vivido naquele ano uma personagem chamada Jeiza que era policial e, mesmo sofrendo com o machismo, não se subordinava aos caprichos do seu parceiro/namorado.

Ao observar as imagens do anúncio, constatamos, primeiramente, as representações narrativa e interativa que possibilitam a compreensão do assunto tratado. Desse modo, o anúncio em vídeo introduzido, no quadro 6, contempla uma representação narrativa, pois a participante representada por Paola Oliveira desenvolve ações que não estão direcionadas a outro participante, caracterizando a estrutura não-transacional. Nesse contexto narrativo, a personagem representava uma mulher forte (Imagem 01), determinada e que parece não deixar que ninguém lhe impusesse restrições.

No que concerne aos significados interativos, na maioria das cenas, notamos que o contato entre participante representado e interativo acontece por meio de um vetor (Quadro 6 - Imagem 03 e 04) que se forma através do olhar da participante representada diretamente para o observador, convidando-o à interação e exigindo alguma reação. No AN-01, notamos ainda que a forma fixa de olhar da personagem (Imagem 03) caracteriza um processo de demanda, pois solicita do observador extrema atenção, compelindo-o a olhar para o anúncio.

Quadro 6 - Representação Narrativa e Interativa

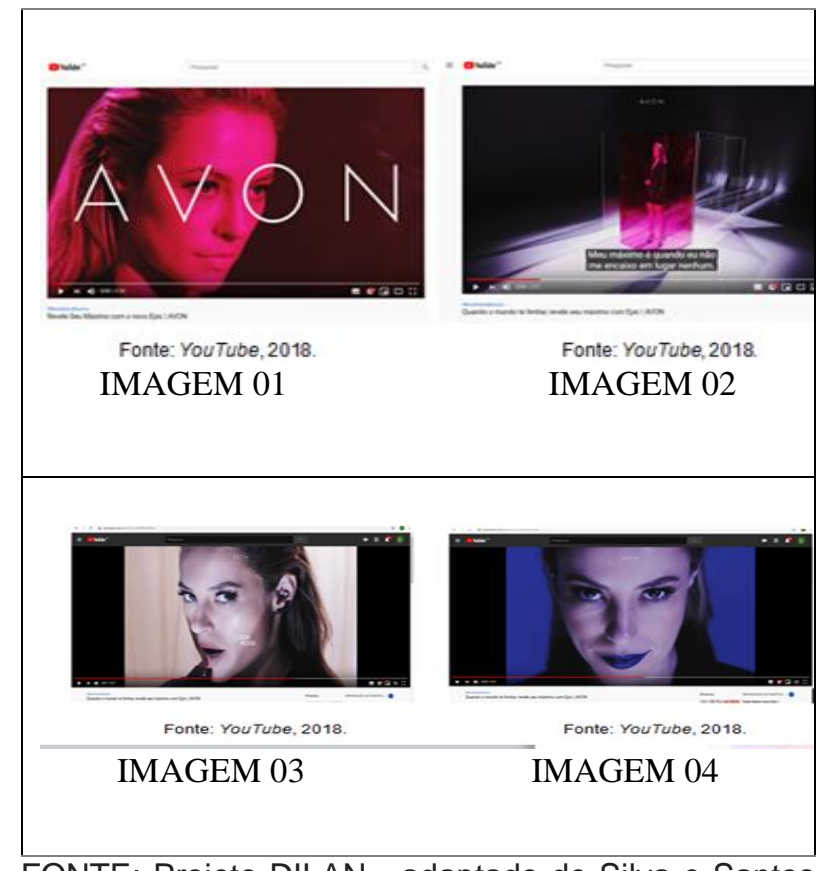

FONTE: Projeto DILAN - adaptado de Silva e Santos (2020)

Quanto ao modo como a participante representada é mostrada, algumas vezes de perto, outras de longe, caracteriza a distância social, que segundo Almeida (2008) é uma espécie de relação mais ou menos imaginária entre os participantes representados e interativos. Entendemos que esse processo é significativo no momento da leitura do 
anúncio e, também, no momento da produção de Comentários.

Outro fato é a representação da personagem no plano fechado e aberto (Quadro 7). Essa percepção de significado imagético constata que a representação da participante em plano fechado (imagem 05) mostra apenas cabeça e ombros, o que indica uma relação de proximidade com o observador. $\mathrm{Na}$ imagem 06, a atriz aparece em plano aberto, pois todo o seu corpo pode ser visualizado, demonstrando uma relação de distanciamento entre os participantes.

\section{Quadro 7 - Representação da personagem}

\section{principal}

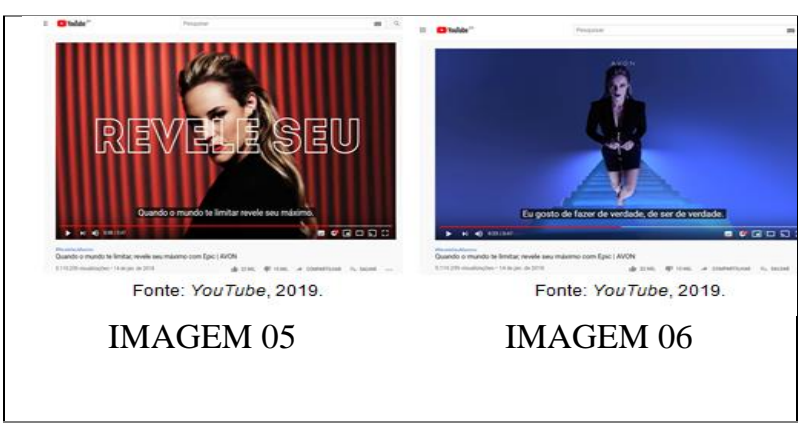

FONTE: Projeto DILAN- adaptado de Silva e Santos (2020)

A seguir, no quadro 8, destacamos a categoria de perspectiva e refletimos sobre ângulos que predominam na constituição da narrativa: frontal, oblíquo ou vertical. Ao analisar o anúncio Epic, constatamos que os ângulos mais utilizados foram o frontal e o oblíquo.

\section{Quadro 8 - Construção da Narrativa}

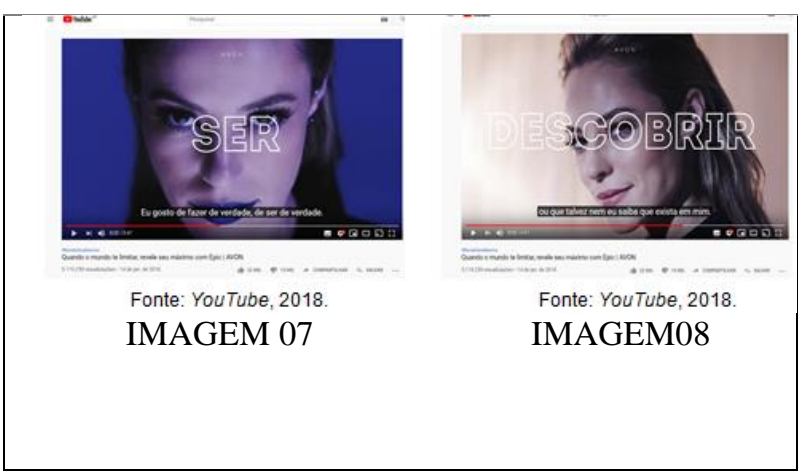

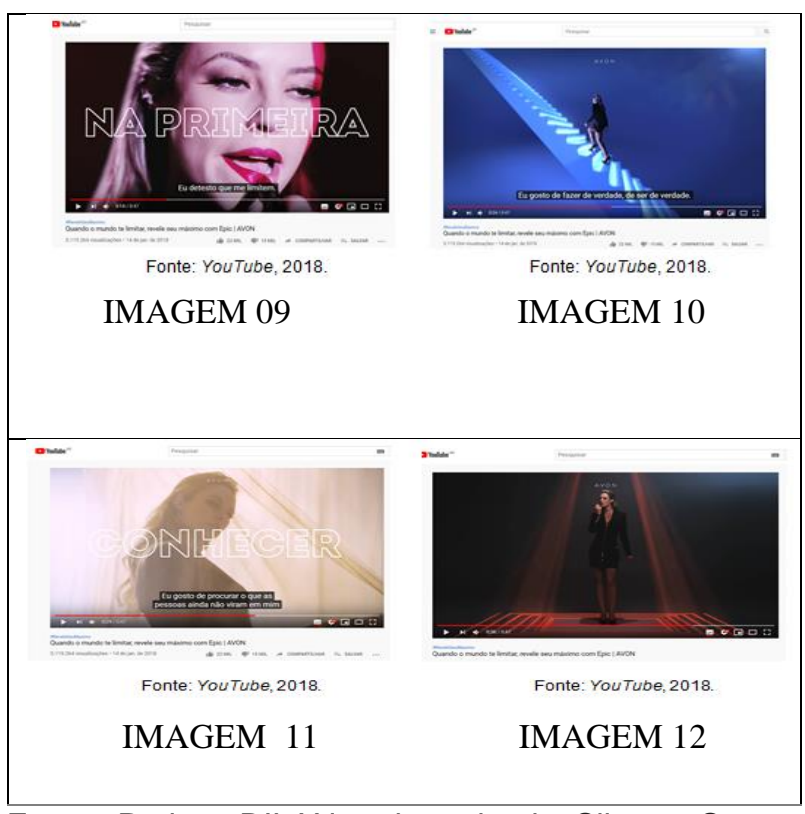

Fonte: Projeto DILAN- adaptado de Silva e Santos (2020)

O ângulo exemplificado na Imagem 7, indica a escolha da posição frontal que sugere um certo envolvimento entre participante representado e observador e, portanto, uma relação de poder igualitária, pois a posição interpretativa que é criada para o participante interativo é de que há um compartilhamento de visão dos sujeitos e o anunciante. Já na Imagem 8, a representação da participante foi dada no ângulo oblíquo, estabelecendo uma relação de alheamento com relação ao observador.

A categoria de modalidade contribui para avaliar o nível de realidade que a imagem possui. Essa mensuração se dá através do modo como alguns recursos como cores, iluminação, brilho e contextualização foram utilizados na composição visual.

$\mathrm{Na}$ Imagem 9 a participante representada realiza a ação de passar batom nos lábios que se caracteriza como uma situação muito comum no universo feminino. Assim, a escolha das cores, o uso do produto e a presença da mulher condizem com uma realidade possível de existir na nossa realidade objetiva e por isso o grau de modalidade é alto em virtude dos valores agregados. Já a Imagem 10, embora possamos identificar a presença da atriz, a realidade não é tratada de forma objetiva, pois a escada do cenário não possui nenhuma base de 
sustentação, apresenta-se solta no espaço e isso sugere que ela não tem fim, indicando, portanto, que a participante está caminhando para o infinito. Esse tipo de representação retrata o nível de modalidade baixo já que a forma como o lugar, a participante e cores foram utilizadas torna a imagem mais próxima do referencial abstrato. Contudo, esclarecemos que mesmo havendo cenas no anúncio em que o grau de modalidade é baixo, a maior parte delas possui alto grau, pois as cores, as ações e os espaços representam a realidade concreta.

Para discutir os significados composicionais presentes no anúncio em vídeo, levamos em consideração três sistemas que são interligados: valor da informação, saliência e estruturação. O primeiro sistema está relacionado com a posição ocupada pela participante na imagem, no caso desse anúncio, a Paola Oliveira ocupa majoritariamente a posição de centralidade, indicado que ela se configura como o núcleo da informação, reforçando a ideia de firmeza e empoderamento que o anunciante pretende transmitir para o público alvo, como podemos observar nas figuras abaixo.

Com relação ao sistema de saliência, percebemos que a participante representada é o elemento mais saliente, pois constantemente ela é apresentada em plano fechado, recebe destaque através da utilização de diferentes cores, jogo de luzes e contrastes e aparece sempre no centro da imagem.

Quanto à estruturação, no anúncio há o predomínio da estruturação forte, pois há em algumas cenas como na imagem 12, a presença de linhas que emolduram a participante, colocando-a em destaque, além do uso das cores branco e preto como pano de fundo da atriz com o objetivo de evidenciá-la. Acreditamos que a estruturação forte pode contribuir para a ênfase dada ao modo como a participante se comporta ao aplicar o produto e também para estabelecer com o público-alvo a ideia de reconhecimento da marca.

\subsection{Percepção dos significados das} imagens - Comentários C1 e C2

Os comentários C1 e C2 foram produzidos por um aluno em etapas distintas do projeto. Neles, foram explícitos como o aluno percebe os significados representacionais, interativos e composicionais presentes nos anúncios em vídeo Revele seu Máximo com o novo Epic, trazendo para seu texto a sua percepção a respeito dos significados promovidos pelas imagens do anúncio em anúncio "Revele seu Máximo com novo Epic" (AN-01) publicado em 2018 (Quadro 7 e 8).

No C1, evidenciamos a predominância de representação conceitual, seguido de narrativa. Esse fato ocorreu na primeira etapa do Projeto Didático e levou o professor a desenvolver atividades que fossem possíveis garantir a percepção de diferentes significados promovidos pela leitura das imagens de anúncios.

\begin{tabular}{|c|c|c|}
\hline $\begin{array}{l}\text { CATEGORIAS } \\
\text { SEMÂNTICAS }\end{array}$ & $\begin{array}{c}\text { PRODUÇÃO } \\
\text { COMENTÁRI } \\
001\end{array}$ & ETAPAS \\
\hline \multirow{4}{*}{$\begin{array}{l}\text { Representaçã } \\
\text { o conceitual }\end{array}$} & $\begin{array}{l}\text { A paola oliveira } \\
\text { uma ótima atriz, } \\
\text { Além de muito } \\
\text { linda }\end{array}$ & <Avaliação> \\
\hline & $\begin{array}{l}\text { ela se destaca com } \\
\text { olhar com o corpo } \\
\text { para fazer o } \\
\text { anúncio sobre o } \\
\text { batom }\end{array}$ & \multirow{4}{*}{ <Sinopse> } \\
\hline & $\begin{array}{l}\text { ela age com } \\
\text { sensualidade }\end{array}$ & \\
\hline & $\begin{array}{l}\text { as imagens } \\
\text { também se } \\
\text { destacam bastante } \\
\text { os tons dos batons }\end{array}$ & \\
\hline $\begin{array}{l}\text { Representaçã } \\
\text { o conceitual e } \\
\text { narrativa }\end{array}$ & $\begin{array}{l}\text { ela faz com que as } \\
\text { mulheres se } \\
\text { interessem pelo } \\
\text { produto que tenha } \\
\text { a vontade de } \\
\text { querer comprar } \\
\text { cada vez mais }\end{array}$ & \\
\hline $\begin{array}{l}\text { Representaçã } \\
\text { o conceitual e } \\
\text { narrativa }\end{array}$ & $\begin{array}{l}\text {,faz com que as } \\
\text { mulheres se sintam } \\
\text { mais lindas e que } \\
\text { o Batom der uma } \\
\text { destaque com } \\
\text { sensualidade de } \\
\text { um novo produto. }\end{array}$ & $\begin{array}{c}\text { <Reafirmação } \\
>\end{array}$ \\
\hline
\end{tabular}


Entendemos que o $\mathrm{C} 1$ é um gênero de texto Interpretação que considera as informações promovidas pelo anúncio, construídas, a partir da percepção dos significados das imagens. Nesta produção, notamos que o escritor identifica a participante representada (Paola Oliveira) e faz uma análise do seu comportamento por meio da leitura visual, interpretando empiricamente a mensagem que ela pretende transmitir através de suas ações no anúncio. Há, também, a identificação do público alvo (participante interativo) e do produto anunciado. Percebemos que não houve o apontamento explícito de qual recurso era mais importante na composição do anúncio, mas diante das observações feitas pelo aluno/escritor, acreditamos que o aspecto visual chamou mais sua atenção. Além disso, ele também não fez referência à linguagem utilizada pela participante representada, desconsiderando o recurso auditivo.

Esse tipo de comentário (Quadro 9), chamado de Interpretação e contemplado na família de Reação a Textos considerada por Rose e Martin (2012), sinaliza três etapas: Avaliação > Sinopse (Descrição) > Reafirmação. Na etapa de Avaliação <Paola Oliveira é uma ótima atriz, além de muito linda>, o escritor, a partir de diferentes vetores sinalizados em diferentes imagens (Imagem 01, por exemplo) constrói um significado conceitual da personagem do NA-01. Esse tipo de etapa se repete em todo C1, avaliando a personagem < Ela (...) age com sensualidade>, por exemplo. Esse fato caracteriza as ações da personagem e o uso do produto (batom). Na Sinopse, há descrição das principais ações da personagem <Ela se destaca com olhar e com corpo para fazer o anúncio sobre o batom (...)>, demonstrando que diferentes vetores, indicados nas imagens do anúncio foram capazes de explicitar a representação narrativa do anúncio. Na Reafirmação, $<$ faz com que as mulheres se sintam mais lindas> 0 aluno concluiu mostrando identificou a estratégia utilizada pelo anunciante para convencer as mulheres a adquirir o produto.

O primeiro comentário $(\mathrm{C} 1)$ se limita, na Sinopse, à descrição da participante representada
Paola Oliveira, descrevendo seus atributos e associando-os à eficácia na divulgação do produto. Notamos que 0 aluno percebe que, além das imagens, o anúncio, também, possui, em menor proporção, outros recursos semióticos importantes como o verbal e o áudio. Além disso, o aluno-escritor apresenta um juízo de valor sobre a produção audiovisual, mostrando assim que ele cumpriu seu objetivo principal que é fazer com que o público-alvo adira a ideia que está sendo apresentada sobre o produto. Contudo, no que se refere às metafunções, não visualizamos indícios de que esse aluno tenha feito referência às categorias da metafunção interativa como, a direção do olhar, ângulo e plano escolhidos.

Já em C2, quadro 8, percebemos que o alunoescritor ampliou os comentários, na Sinopse, apontando não só elementos que correspondem ao significado representacional, como a identificação da participante representada e o produto, mas também ao significado composicional quando chama atenção para o uso intencional de cores, tons, jogo de luzes e escolha dos cenários que contribuem para transmitir a sensação de empoderamento da mulher que usa o batom. Dessa forma, o C2, no quadro 8, também, caracterizamos como uma Interpretação, composta por uma Sinopse > Reafirmação. Na Sinopse, há vários significados originados da percepção da imagem do anúncio pelo estudante, mas a ênfase foi dada ao modo como os elementos imagéticos foram organizados para formar um todo significativo, garantindo a representação narrativa. Logo, a maneira como os elementos da imagem se uniram para integrar com os elementos representacionais e interativos do anúncio em vídeo, levaram o aluno-escritor a explicitar mais informações do anúncio estudado, considerando as categorias de valor da informação, saliência, estruturação/enquadramento, apontadas por Kress e van Leeuwen (2006), ao caracterizar a sintaxe visual de um texto imagético.

Deste modo, acreditamos que, no desenvolvimento do projeto didático em sala de aula, esse aluno (C2 - Quadro 10) passou a perceber que as imagens são portadoras de diferentes significados e, no contexto publicitário, não são utilizadas como 
mero adorno, mas associadas com o elemento verbal desempenham papel importante na construção de significados e, consequentemente, no processo de comunicação.

Quadro 10 - Percepção de significados materializados no C2-A1

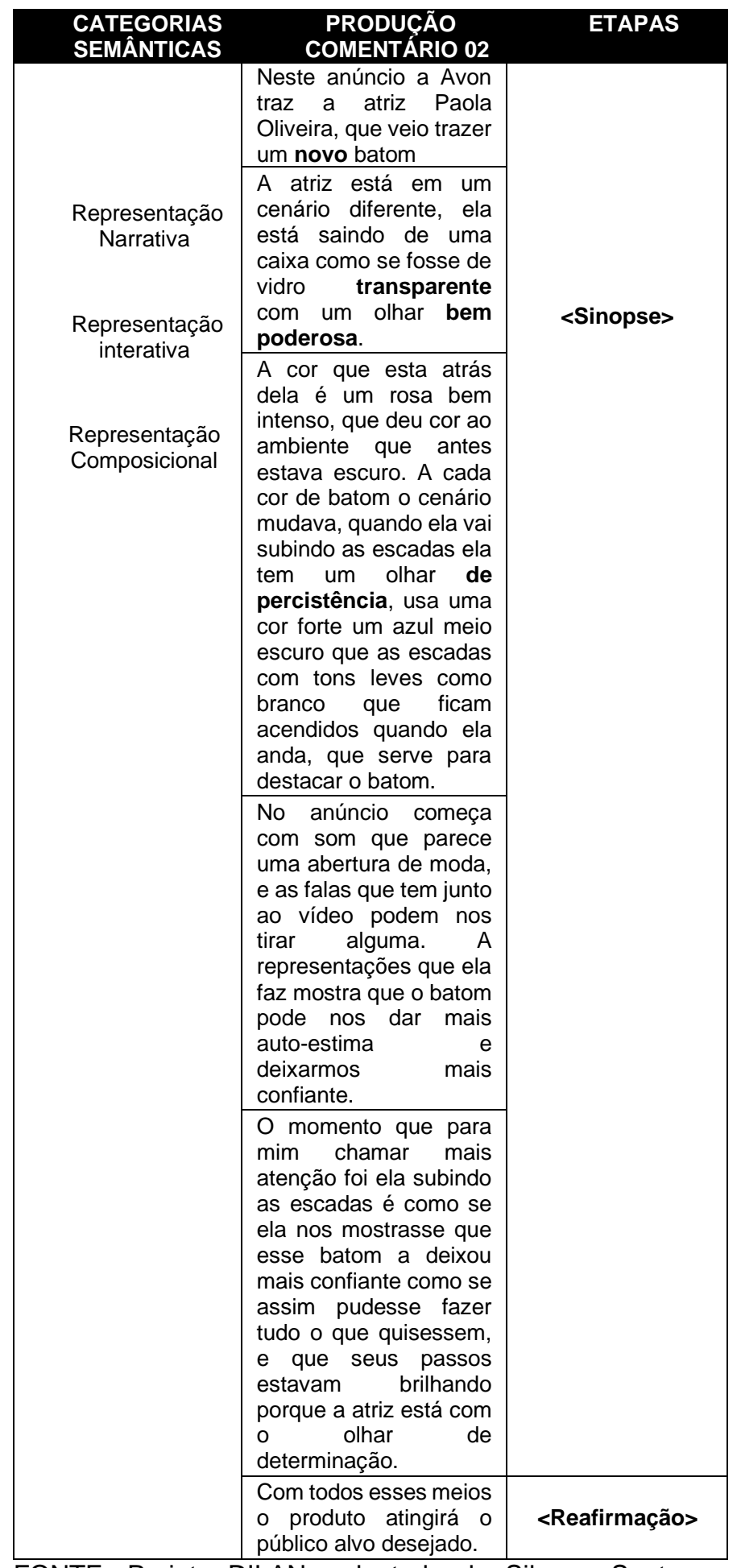

FONTE: Projeto DILAN- adaptado de Silva e Santos (2020)
Em síntese, o comentário C2 é composto de enunciados que sintetizam os significados das imagens do anúncio. Esse fato sinaliza o diálogo entre as funções representacional, interativa e composicional e sua relação com a produção de comentários e contexto social dos estudantes.

Do ponto de vista do significado representacional, os recursos da imagem permitiram representar a participante envolvida, no âmbito da representação narrativa, por exemplo, nas ações (Paola Oliveira, Empresa Avon e produto Batom) e acontecimentos (Neste anúncio a Avon traz a atriz Paola Oliveira, que veio trazer um novo batom) e, no âmbito da representação conceitual, há vários atributos a Paola (a atriz (...) transparente com um olhar bem poderosa), ao produto Batom (... um novo batom).

$\mathrm{Na}$ construção do significado interativo, notamos que, no C2, há uma relação construída entre a participante, representada Paola, e o leitor. Dessa forma, o aluno-escritor traz para o C2 diferentes graus de interpelação para leitor-aluno (contato), de intimidade (distância social), de envolvimento ou identificação (atitude) e de maior ou menor simetria com relação ao leitor (poder). E, na construção do significado composicional, observamos como os elementos representados são alocados na imagem e como aluno-escritor trouxe interpretações envolvendo o valor da informação. Nessa perspectiva, foram expostas no C2, construções culturais da Avon na comunidade que o aluno está inserido.

Para mostrar a pertinência de um projeto de leitura e de escrita, inspirado no Ler para Aprender (MARTIN; ROSE, 2012), situamos o este estudo na proposta de leitura de imagens considerando as metafunções representacional, interativa e composicional (KRESS; VAN LEEUWEN, 2006) na atribuição dos sentidos das imagens de um anúncio em vídeo. Optamos, portanto, analisar dentro da materialidade visual, a contribuição da imagem para a compreensão leitora e escritora do estudante. 


\section{Considerações finais}

A partir da inserção de um projeto de leitura e escrita em sala de aula do Ensino Fundamental, considerando as principais etapas do Projeto Ler para Aprender (MARTIN; ROSE, 2012), a principal contribuição de nosso trabalho reside na possibilidade a relação entre o verbal (oral e o escrito) e não verbal (imagem) no processo de interpretação de textos. Dessa forma, as reflexões realizadas, neste artigo, indicam que a Gramática do Design Visual fazendo parte de um projeto didático de leitura e de escrita se configura como mais uma ferramenta teórica e metodológica para o estudo de imagens em sala de aula, subsidiando o ensino da leitura e da escrita e partindo da ideia de que a linguagem não verbal (imagem) se constitui como estruturas visuais passíveis de interpretação, assim como acontece com a linguagem verbal (escrita e/ou oral).

Este artigo, inspirado no Ciclo de Ensino Aprendizagem Ler para Aprender, e desenvolvido em oficinas pedagógicas, procurou romper com alguns paradigmas com relação ao ensino de língua materna, propondo uma reflexão sobre a forma como nos comunicamos e como construímos significados ao ler anúncios publicitários.

Os resultados das oficinas pedagógicas, inspiradas na Pedagogia de Gênero, especialmente no Ciclo de Ensino e Aprendizagem Ler e Aprender mostram que é possível ampliar o letramento multimodal e garantir a inclusão de gêneros em aulas de leitura e de escrita. Nesse diálogo entre ler e escrever, notamos um maior envolvimento dos estudantes do 9ำ ano do Ensino Fundamental com o texto verbal e não verbal, devido às configurações textuais, que trouxe à tona o letramento multimodal. $\mathrm{E}$ as atividades vivenciadas nessa pesquisa de caráter didático interventivo podem ser úteis para o professor refletir sobre a importância de levar em consideração - letramento multimodal nas escolas, pois abordar a imagem, no contexto da sala de aula, significa sistematizar o que já é feito fora dela e isso pode fortalecer os laços existentes entre a escola e mundo, tornando a aprendizagem muito mais significativa para esses novos sujeitos que fazem parte da sociedade extremamente visual.

Com relação aos Comentários escritos em sala de aula durante a vivência do projeto, constatamos que, no gênero de texto (Interpretação) produzido na primeira etapa, os alunos se ativeram a descrição das imagens observadas, destacando os elementos de modo isolado; não percebiam as imagens como textos que possuem um conteúdo de significação. Assim, notamos a construção de uma estrutura textual predominantemente descritiva em que os constructos de sentidos foram baseados no conhecimento de mundo que eles traziam. Portanto, nesses comentários (C1), não visualizamos o diálogo entre as duas linguagens - a verbal e a não verbal mas, apenas a apresentação de informações explícitas, principalmente, pela linguagem verbal (escrita). O segundo comentário, produzido na última etapa do projeto (C2), demonstra que os alunos conseguiram ampliar as informações e a leitura passa da mera verbalização do que é visto para uma leitura inferencial considerando as linguagens - a verbal e a não verbal e construindo significados por meio da reflexão sobre as relações entre imagens e textos escritos, relacionando-os ao contexto de produção dos anúncios em vídeo.

Diante desses resultados, ressaltamos a necessidade do diálogo entre o Projeto Ler para Aprender com as metafunções da linguagem imagética (considerando a GDV) como apoio teórico metodológico para o professor, já que a GVD pode ser utilizada como uma ferramenta crítico-analítica para analisar sistematicamente estruturas visuais e para a conscientização de que as imagens não se constituem como veículos dissociados dos contextos sociais, político e cultural. Assim, destacamos a relevância desse estudo para o ensino dos gêneros que circulam em ambientes digitais, pois acreditamos que a abordagem teórica e metodológica seguida neste estudo pode contribuir para a prática pedagógica de outros professores de Língua Portuguesa e fazê-los olharem para os gêneros do contexto do digital como objeto de ensino-aprendizagem e para a plataforma do YouTube como uma ferramenta potencialmente 
importante para o ensino e aprimoramento do letramento multimodal.

\section{Referências}

ALMEIDA, D. B. L. Do texto às imagens: as novas fronteiras do letramento visual. In: PEREIRA, R. C.; ROCA, P. (orgs.) Linguística Aplicada - um caminho com diferentes acessos. São Paulo: Editora Contexto, 2009, p. 173-202.

BRASIL, Secretaria de Educação Fundamental. Parâmetros Curriculares Nacionais: Língua Portuguesa. Brasília: MEC/SEF, 2008. p.144.

BRASIL. Base Nacional Comum Curricular. Brasília: MEC, 2018.

HALLIDAY, M. A. K. Estrutura e função da linguagem. In: LYONS, J. (Org.). Novos horizontes em linguística. São Paulo: Cultrix, 1976. p. 134-78.

HALLIDAY, M.A.K. An Introduction to Functional Grammar, London: Edward Arnold, 1985.

HALLIDAY, M.A.K. An introduction to Functional Grammar. London: Edward Arnold Publishers, 1985.

HALLIDAY, M. A. K.; R. HASAN. Language, context, and text: aspects of language in a social-semiotic perspective. Oxford: Oxford University Press, 1989.

KRESS, G.; VAN LEEUWEN, T. Reading images: the grammar of visual design. London, New York: Routledge, [1996], 2006.

MARTIN, J.R. On of three traditions: genre, functional linguistics, and the "Sydney School". In: ARTEMEVA, N. and FREEDMAN, A. Genre studies around the globe: beyond the three traditions. Inkshed publications, p. 31-79, 2016.

MUNIZ DA SILVA, E.C. Gêneros na teoria sistêmicofuncional. D.E.L.T.A., 34.1,(305-330), 2018.

PAVIANI, N. M. S.; FONTANA, N. M. Oficinas pedagógicas: relato de uma experiência. Conjectura, v. 14, n. 2, maio/ago. 2009.

ROTHERY, J. Making changes: developing an educational linguistics. Hasan \&Williams. 86-123, 1996.

ROTHERY, J; MARTIN, J. R. Writing Project Report Namber 1. Department of Linguistics. University of Sidney, 1979.

ROSE, D.; MARTIN, J. R. Learning to Write, Reading to Learn: Genre, Knowledg and Pedagogy in the Sydney School. London: Equinox, 2012.

ROSE, D. Engaging and supporting all our students to read and learn from reading. In PETAA: Primary English Teaching Association Austrália, 2016. Disponível em. Acesso em: 20 de nov. 2020.

SILVA. S.R.E. Da leitura de anúncios em vídeo à produção de comentários: um estudo de significados à luz da Gramática do Design Visual. Dissertação de Mestrado. UPE/Mata Norte, 2020.

\section{COMO CITAR ESSE ARTIGO}

ALBUQUERQUE BARBOSA, MARIA DO ROSÁRIO DA SILVA; SANTOS SILVA, Érika Regina dos. AMPLIANDO O LETRAMENTO ESCOLAR: DA LEITURA DE ANÚNCIOS EM VÍDEO E A PRODUÇÃO DE COMENTÁRIOS. Signo, Santa Cruz do Sul, v. 46, n. 86, maio 2021. ISSN 1982-2014. Disponível em: <https://online.unisc.br/seer/index.php/signo/article/vie w/16027>.

doi:https://doi.org/10.17058/signo.v46i86.16027. 